\title{
Simple Plastic Model for Shear Critical SFRC Beams
}

\author{
Nino Spinella ${ }^{1}$; Piero Colajanni ${ }^{2}$; and Antonino Recupero ${ }^{3}$
}

\begin{abstract}
A simple physical model, for prediction of ultimate shear strength of steel fiber-reinforced concrete (SFRC) beams is developed on the basis of a plastic approach originally proposed for reinforced concrete beams without stirrups. It is founded on the hypothesis that cracks can be transformed into yield lines, and thus is know as crack sliding model (CSM). First, the CSM is improved to take into account the shear strength increase for deep beams. due to the arch effect. Then, the effectiveness factors for fibrous concrete under biaxial stresses are evaluated, taking into account the postcracking tensile strength of SFRC and its ability to control slippage along shear cracks. With the aim of providing a handy and fast tool for design of SFRC beams without stirrups. a simplified design model is also derived. Finally. the proposed models are validated by the results of a large set of experimental tests taken from literature.
\end{abstract}

DOI: $10.1061 /($ ASCE)ST.1943-541X.0000127

CE Database subject headings: Steel: Fibers: Reinforced concrete; Design: Concrete beams: Shear strength.

Author keywords: Steel fiber-reinforced concrete; Plastic theory: Design; Shear critical beams.

\section{Introduction}

Due to the brittle behavior of plain concrete in tension. shear failure in reinforced concrete (RC) beams without transversal reinforcement is generally catastrophic. Shear failure of an RC beam without stirrups can occur with a variety of failure types: in deep members due to the crushing of an inclined compression strut: in slender members when the principal tensile stress within the shear span exceeds the tensile strength of concrete and a diagonal crack propagates through the beam web. These failure mechanisms are typical of many structural elements without shear reinforcement, and not just for beams, like wall and foundation of retaining wall; upper and lower slabs of cut-and-cover tunnel: and deck slab of bridge (Muttoni and Ruiz 2008).

The request of always providing a minimum shear reinforcement is common to all international codes: however the recent ACI Code [American Concrete Institute (ACI) 20(08] allows use of steel fiber-reinforced concrete (SFRC) to construct beams, with some mechanical and geometrical limitations, to avoid the brittle failure due to shear action.

Several experimental studies have shown that in RC beams without shear reinforcement. a small quantity of steel fibers in the mixture increases the shear strength and the structural element ductility (Imam et al. 1998). The use of fibers as shear reinforcement demonstrated its ability to boost the shear capacity of structural elements or to replace. in part. the vertical stirrups. (Mansur

${ }^{1}$ Postdoctoral Student. Dipartimento di Ingegneria Civile. Università di Messina. Italy (corresponding author). E-mail: spinella (a ingegneria. unime.it

ZAssociate Professor. Dipartimento di Ingegneria Civile. Università di Messina. Italy. E-mail: pieroc@ingegneria.unime.it

Assistant Professor. Dipartimento di Ingegneria Civile. Università di Messina. Italy. E-mail: arecupero (a unime. it

Note. This manuscript was submitted on October 30. 200)8: approved on September 7. 20099: published online on October 8. 20099. Discussion period open until September 1. 2010); separate discussions must be submitted for individual papers. This paper is part of the Journal of Structural Engineering. Vol. 136. No. 4. Aprii 1. 2010. (1)ASCE. ISSN (0733$9445 / 201(0 / 4-390-400 / \$ 25.00$. et al. 1986: Li et al. 1992: Kwak et al. 2002: Cucchiara et al. 2004). Moreover, tests recently carried out by Thomas and Ramaswamy (2006) showed the possibility to cast prestressed concrete T-beams with stirrups having steel fibers over partial and full depth. still obtaining interesting results in terms of shear strength. Actually, codes do not provide specific rules to design a mixed shear reinforcement with both fibers and stirrups. However the experimental evidence encourages this approach. and it would avoid congestion of bars and allow lower costs.

Recently, fibers have been employed in high-strength concrete, with compressive strength more than $50 \mathrm{MPa}$, having more inherent brittleness. Their use is attractive for longer span and taller structures. as well as for earthquake-resistant structures. Fibers can give ductility to high-strength concrete members and, in specific situations. they can turn the brittle shear failure of beams in favor of flexure failure mode (Ashour et al. 1992: Khuntia et al. 1999).

The major difference in the shape of constitutive laws between plain and fibrous concrete lies in their different postpeak behaviors, especially for SFRC under tensile stress. Fibers increase the residual tensile strength of the composite. enlarging the softening branch of the stress-strain curve in compression and, hence, significantly enhance the shear strength of short and long beams.

With the aim of predicting the ultimate shear capacity of SFRC beams without stirrups, numerous empirical or semiempirical methods have been suggested. Several researchers have extended known relationships, proposed in literature for plain concrete beams, to fibrous concrete members. providing an additional contribution to shear strength depending on the amount of fibers (Ashour et al. 1992: Campione et al. 2006).

Semiempirical models are usually generated by a regression analysis of SFRC beam test data for a few fiber types and volume percentages $V_{f}$ and. hence, their use is restricted to the limited range of variation of fiber parameters investigated in experimental tests. Therefore, the structural use of fiber-reinforced concrete in the building industry has not yet been fully achieved as a general mechanical model is not widespread.

An attractive alternative approach to the above-cited semiempirical models is provided by the plastic theory that has long been applied with success to RC structural members (Nielsen 
19991. On the bases of this theory and limit analysis concepts. many rational formulations have been proposed in literature for prediction of shear capacity of RC beams.

Nielsen (1999) assumed that stress fields transfer the load directly to the support points of the beam by satisfying the yield material criteriat. and he evaluated the shear strength of $\mathrm{RC}$ beams without stirrups by applying the lower bound approach of plastic theory. The obtained simple plastic model is known as original plastic solution.

Several papers (Zhang 1997: Vecchio 2000a) concerning plain concrete shear behaviors have shown that slips along the crack can delay or prevent the development of direct strut action spanning between the loading and the support points of beams. These certainly imply that sliding displacements can occur along the crack and the failure crack can originate from a generic section between loading and support point. This failure mechanism is typical of slender heams and it is taken into account by plastic theory in an interesting modification of the original plastic solution. called crack sliding model (CSM) and proposed by Zhang (1997).

These plastic theory formulations have been originally suggested for plain concrete without fibers. When SFRC elements are considered, indeed, the well-known shear failure mechanisms of $\mathrm{RC}$ beams without stirrups are not drastically change by the presence of fibers. However, improving mechanical properties of concrete, fibers help structural elements to resist shear actions due to large ductility of the fibrous concrete mixture. Furthermore, the plastic theory basic hypothesis of perfect-rigid plastic constitutive behavior of material is in good agreement with the observed constitutive behavior of SFRC, where a non-negligible postpeak strength branch is always present.

In this paper, aiming at providing a simple physical design model, the formulation of CSM for the evaluation of ultimate shear strength of RC beams without stirrups is first generalized to also predict the ultimate shear capacity of short RC members. Then. it is moditied to predict the shear strength of fibrous concrete beams taking into account the ability of fibers to contain shear crack slips and the width of cracks. This is achieved by defining original analytical expressions of the effectiveness factors for SFRC to estimate the effective strength of fibrous concrete in compression and tension. and identifying the cross section of the beam where the critical shear crack starts to propagate along the web.

The proposed formulation is validated by means of the results of a large database of experimental tests collected in literature, and the effectiveness is proved by favorable comparison with several known relationships (Sharma 1986: Narayanan and Darwish 1987: Al-Ta an and Al-Feel 1990: Ashour et al. 1992: Imam et al. 1998: Khuntia et al. 1999: Kwak et al. 2002; Campione et al. 20(06).

Moreover. a simplified version of the proposed model is derived. A numerical example is reported to demonstrate that the compact proposed formula provides a friendly and reliable tool for designers, to quickly estimate the shear strength of SFRC beams without stirrups.

\section{General Formulation of Crack Sliding Model}

In theory of plasticity applied to concrete structural elements. reinforcement is assumed to resist forces in axial direction only. with yield stress equal to $f_{1}$. Concrete is assumed to behave as a rigid, perfectly plastic material. obeying the modified Coulomb failure criterion with the associated flow rule (Nielsen 1999).

At failure, the cracked concrete in compression is simultaneously subjected to compression and tensile strains, the latter in a direction which is orthogonal to compression strains. Therefore. it exhibits a reduced strength compared to the uncracked concrete in uniaxially compression. This physical behavior is called compression softening and can be recognized in the plastic theory by the effectiveness factors for concrete. A similar interpretation of this phenomenon is also given by other theories, such as the modified compression field theory (MCFT) (Vecchio and Collins 1986).

In the original plastic solution the effective compressive strength is evaluated in the following form:

$$
\begin{aligned}
f_{c \cdot c f}=v_{c} f_{c}= & \left\{\left(3.5 / \wedge \overline{f_{c}}\right)[0.27(1+1 / \sqrt{h})]\right. \\
& \left.\times(0.15 r+0.58)\left[1.0+0.17(a / h-2.6)^{2}\right]\right\} f_{c}
\end{aligned}
$$

where $v_{c}=$ effectiveness factor for plain concrete in compression: $f_{c}=$ compressive cylinder plain concrete strength, $a=$ shear span: $h$ and $b=$ height and width of beam cross section: $A_{s}=$ longitudinal reinforcement area: and $r=100 A_{s} / b h$ longitudinal reinforcement percentage. The last term in Eq. (1). $\left[1.0+0.17(a / h-2.6)^{2}\right]$. has been introduced by Rojkjær in 1979 (Nielsen 1999) and proves that $v_{c}$ is a function of shear span-height ratio $a / h$, which is extremely inconvenient, but necessary because the original solution of plastic theory shows a strong dependency by geometric characteristics of beams, underestimating the ultimate average shear stress at failure for small and high values of $a / h$ and overestimating it for intermediate values of $a / h$ (Nielsen 1999).

Thus, for a simply supported rectangular beam loaded with two symmetrically point loads [Fig. 1(a)], the ultimate average shear stress may be evaluated using the upper bound approach of the limit analysis. On the basis of the beam failure mechanism in Fig. 1(a). the equality $W_{i}=W_{\text {, }}$ between internal and external works and the upper bound solution. respectively, gives

$$
\begin{gathered}
\frac{1}{2} f_{c \cdot c h} b(1-\sin \gamma) \frac{h}{\sin \left(90^{\circ}-\gamma\right)} u=P_{u t} u \\
\tau_{u}=\frac{P_{u}}{b h}=\frac{1}{2} f_{c \cdot c t}\left[\sqrt{1+\left(\frac{a-x}{h}\right)^{2}}-\frac{a-x}{h}\right]
\end{gathered}
$$

with $x$ the distance from the support of the section where the crack starts at the bottom level of the beam; $\cot \gamma=(a-x) / h$ : and $\tau_{1 /}$ the average shear stress at failure. Minimizing with respect to $x$ the analytical expression of $\tau_{t}$ in Eq. (3), the original plastic solution $(x=0)$ is obtained.

However, Zhang (1997) provided some interesting modifications to the original plastic theory. based on the consideration that the slippage along a crack originated in a generic section of the shear span may be more dangerous than slippage along the theoretical cracking line between support and load application point on the top level of beam. as is assumed in the original plastic solution. Thus, a different starting section of the critical diagonal crack must be determined.

To this aim. the load level necessary to fully develop a diagonal crack in a generic section of the beam along the shear span is determined. Assuming a semicircular crack [Fig. 1(b)] for the beam, the moment equation on the crack tip [marked $A$ in the Fig. (b)] with a statically equivalent straight tensile stress $f_{c 7, \%}$ gives the average cracking stress $\tau_{c r}$ as follows: 


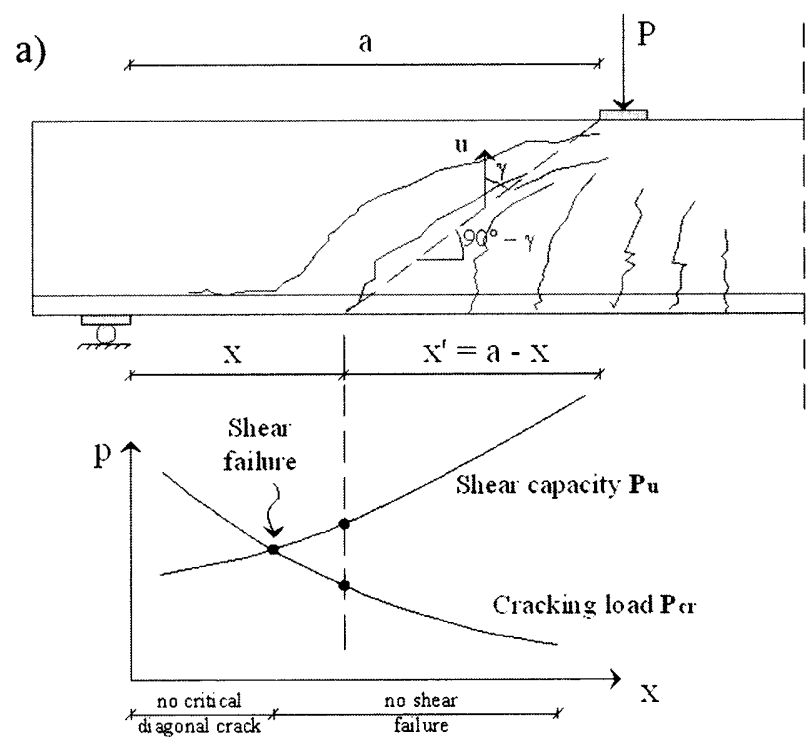

b)

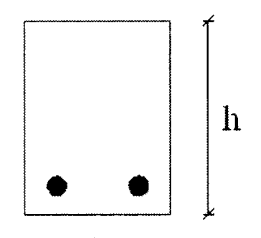

b

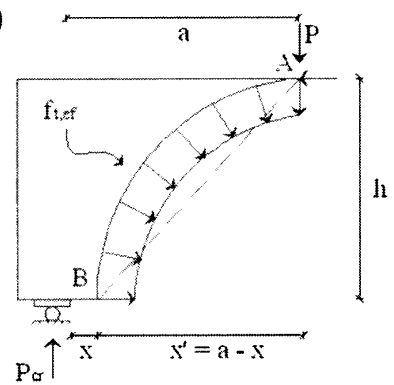

Fig. 1. Crack pattern in a beam without stirrups at: (a) shear failure; (b) first cracking

$$
\tau_{c r}=\frac{P_{c r}}{b h}=\frac{1}{2} f_{c t c t} \frac{1+[(a-x) / h]^{2}}{a / h}
$$

where the effective tensile strength of plain concrete for a beam with height $h$ is $f_{c t e f}=0.156 f^{2.3}(h / 100)^{-0.3 .3}$. The latter expression is obtained (Zhang 1997) by a regression analysis on some test results.

The distance from the support of the starting section of the critical diagonal crack $x$ is obtained by equating $\tau_{n}[\mathrm{Eq} .(3)]$ and $\tau_{c r}$ [Eq. (4)]. which is the intersection of the shear capacity and cracking load curves in Fig. I(a). The two curves do not always intersect because the cracking load curve can be lower than the shear capacity curve within the $x$ range. In these cases, the shear capacity coincides with the value of the original plastic solution $(x=0)$.

Introducing this new concept. Zhang (1997) eliminated the dependence of $v_{c}$ by shear span-height ratio $a / h$ and proposed to evaluate the effectiveness factor for plain concrete in compression as a product of two terms

$$
v_{c}=v_{、} v_{0}=v_{\mathrm{s}}\left\{\left(5.6 / \overline{f_{i}}\right)[0.27(1+1 / \bar{h})](0.15 r+0.58)\right\}
$$

where $v_{s}=0.50=$ sliding reduction factor due to the reduced cohesion of cracked concrete when the yield line follows the diagonal crack path or crosses many cracks; and $v_{0}=$ modified part of the empirical formula (1). used in the original plastic solution (Nielsen 1999). where the term dependent on $a / h[1.0$ $\left.+0.17(a / h-2.6)^{2}\right]$ is no longer necessary. It is interesting to observe that recently the disturbed stress field model. which updates the MCFT. has adopted a coefficient analogous to $v$ to take into account the influence of crack sliding on compression softening (Vecchio 2000b).

\section{Arch Effect Contribution}

The CSM is a mechanical model to determine the ultimate shear load of plain concrete beams without stirrups. It has been validated by Zhang (1997) on a large database of data collected in literature. The tests considered by the writer for the model corroboration are characterized by values of $a / h>2$; thus most specimens collapse for diagonal tension. and the beam action is the principal shear resistance mechanism. Fig. 2 shows the dependence of the relative flexural capacity $\left(M_{u} / M_{f l}\right)$ of the shear spaneffective depth $(a / d)$ for a plain concrete beam. where the nominal flexural capacity is evaluated as suggested by ACI code (ACI 1983)

$$
M_{f l}=b d^{2} \rho f_{i}\left[1-\left(\rho f_{v}\right) /\left(1.7 f_{c}\right)\right]
$$

where $f_{v}=$ yield steel strength and $\rho=$ geometrical percentage of longitudinal reinforcement. The ultimate moment $M_{n}$ is calculated with CSM and by the model proposed by Russo et al. (1991) for plain concrete beams. This model provides the contribution of both beam and arch resistance mechanisms in the whole range of $a / d$ values. The CSM validates numerical results only for $a / h$ $>2$ and fails for $a / h<2$ because it is not able to provide a good estimation of the arch action. This is due to the shear failure mechanism assumed by Zhang (1997) at the basis of his mechanical model. which is an adequate choice just for slender beams.

To eliminate this drawback, the CSM is here improved. retaining the correlation of the effectiveness factor for plain concrete in compression by the $a / h$ ratio for $a / h<2$, i.e.. reintroducing the additional term $\left[1.0+\left(0.17(a / h-2.6)^{2}\right]\right.$ (already existing in the

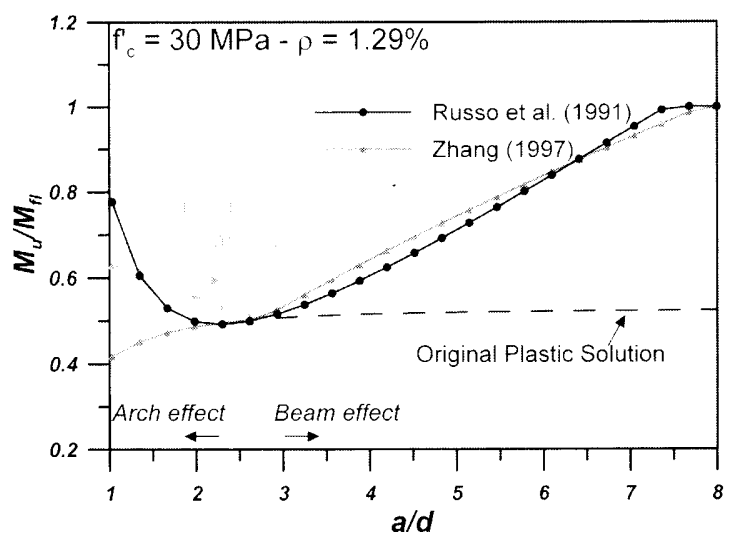

Fig. 2. Relative flexural capacity evaluated with CSM and Russo et al. 11991$)$ model 


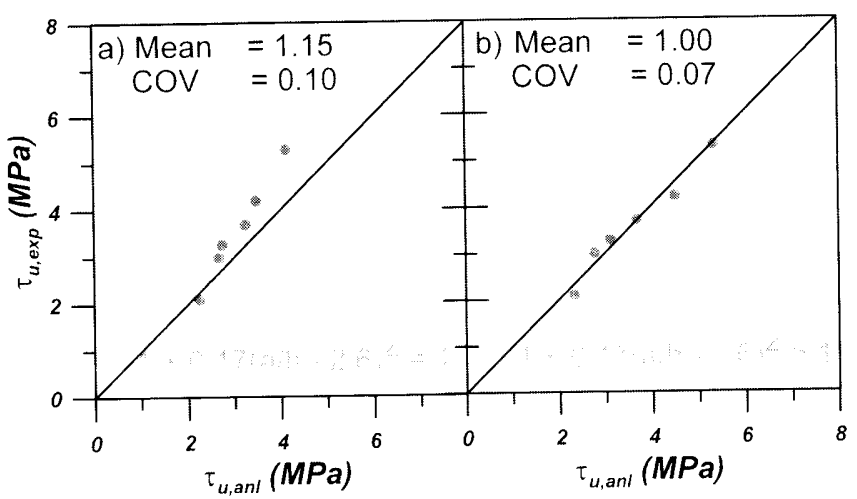

Fig. 3. Comparison between experimental and analytical results for plain concrete deep beams: (a) original: (b) modified formulation of CSM

original plastic solution) in Eq. (5). but only for $a / h \leqslant 2.6$ The increased accuracy obtained by the modified version of the CSM is shown by the dashed line in Fig. 3. where the noticeable effectiveness increment in the assessment of relative flexural capacity for deep beams can be recognized.

Furthermore, a comparison with experimental results pertaining to six deep high-strength concrete (HSC) beams tested by Cho and $\operatorname{Kim}(20(03)$ is performed. The specimens have $a / h$ ratio in the range 1.20-2.06 and are over reinforced in flexure. In Fig. 3 , the experimental values of the ultimate shear stress $\left(\tau_{\text {tuxp }}\right)$ are plotted versus the analytical ones $\left(\tau_{\text {tranl }}\right)$. The numerical predictions are provided by two different expressions: by using the original formulation proposed by Zhang (1997) [Fig. 3(a)] with the effectiveness factor for the concrete in compression independent of the shear span-height ratio: and by adopting the generalized version of the CSM [Fig. 3(b)]. where the dependence of $v_{0}$ on the $a / h$ ratio for short beams is taken into account as explained above.

Figs. 3( $a$ and $b)$ show that the modification here introduced in the original formulation of CSM is able to provide a more realistic estimation of the arch mechanism contribution to the shear strength of the HSC short beams considered. The modified formulation of the CSM is now capable of recognizing the failure mode of beams covering a large range of $a / h$ values.

\section{CSM for Fibrous Concrete Beams}

Flattened stress-strain relationships in the postpeak range of fibrous concrete in compression and tension make the SFRC more suitable than plain concrete for the application of the plastic theory. Moreover. the presence of fibers in the matrix induces the reduction of slips along cracks. To apply the plastic theory to fibrous concrete beams, the most important issue is the use of reliable constitutive laws for fibrous concrete. aiming to define the analytical expressions of effectiveness factors for SFRC in compression and tension.

For fibrous concrete in compression. the effective compressive strength $f_{\text {if }}$ is now related to the cylinder strength $f$, by the effectiveness factor $v_{f f}\left(f_{f, f}=v_{t, f}\right)$. which accounts for the true crack sliding resistance and ductility of material. Few expressions have been proposed for the effectiveness factors in compression of fibrous concrete (Nielsen 1999). Fibrous concrete shows a uniaxial compression strength similar to plain concrete. but less softening in the postpeak branch is always observed when a small quantity of fibers is placed in the mixture (Cucchiara et al. 2004). Thus for fibrous concrete, a value of effectiveness factor in compression higher than plain concrete is reasonably expected.

The residual tensile stress of SFRC also plays a key role in the shear failure mechanism of the beam, especially for slender structural elements. The analytical relationship proposed by Foster et al. (2006), namely the variable engagement model (VEM(06). for fibrous concrete in direct tension is adapted to evaluate the effective tensile strength $\left(f_{i t f, e f}=v_{t f} f_{c t f}\right)$. The VEM06 considers that slip between fibers and concrete matrix occurs before the full bond stress is developed, and the fibers fracture themselves before being pulled out across a crack. The constitutive law of tensile stress versus crack opening displacements (w) is the simple sum of stress contributions by matrix and fibers

$$
\sigma_{c f}(w)=\sigma_{c}(w)+\sigma_{i}(w)
$$

According to VEMO6, the fibers are mechanically anchored to the matrix and some slips between fiber and matrix must occur before the anchorage is engaged. The crack opening $w$ for which the fiber becomes effectively engaged in the tension carrying mechanism is termed the engagement length. and evaluated as $w_{\text {, }}$ $=\alpha \tan \theta$, where $\alpha=d_{f} / 3.5$ is a material parameter and $\theta$ is the fiber inclination angle with respect to the crack plane.

When $w$ is equal or higher than $w_{e}$, the force in a single fiber is $P_{f}=\pi d_{f} \tau_{f}\left(l_{a}-11\right)$. with $l_{a}=$ initial length of embedment of the fiber and $\tau_{f}=$ mean shear stress between the fiber and the matrix. measured along the remaining portion of embedded fiber $\left(I_{a}-w\right)$. Integrating the expression of single fiber force. $P_{f}$. over a plane of unit area. the tension stress bridging provided by fibers across the crack is obtained

$$
\begin{gathered}
\sigma_{f}(w)=f_{c f}\left[\frac{\tan ^{-1}(w / \alpha)}{\pi}\left(1-\frac{2 w}{l_{f}}\right)^{2} F_{\tau}\right] \\
F_{\tau}=\beta_{\tau} V_{f}\left(l_{f} / d_{f}\right)
\end{gathered}
$$

where $F_{\tau}=$ parameter here defined. formally analogous at the fiber factor $F=\beta V_{f}\left(l_{f} / d_{f}\right)$ originally introduced by Narayanan and Darwish (1987). The fiber bond factor $\beta$ may vary from 0.5 to 1.0 , depending on the fiber geometry (hooked, crimped, or straight ended) and on the concrete matrix characteristics. Unlike $\beta, \beta_{\tau}$ in Eq. (9) may be directly evaluated as the ratio between the mean fiber-matrix shear stress and the strength in direct tension of the material.

To predict the value of residual tensile strength of fibrous concrete at the shear failure of beam, the contribution given by the matrix. $\sigma_{1}\left(w^{\prime}\right)$, is here computed by a simple linear law (Vecehio $200(0)$ )

$$
\sigma_{r}(w)=1-w / w
$$

where $w_{t}=2 G_{c} / f_{c}=$ maximum crack width for the matrix. The iracture energy of plain concrete, $G_{c}=0.00375 f^{2} a_{g}^{1+}(\mathrm{N} / \mathrm{mm})$, is evaluated depending on the maximum aggregate size $a_{g}$ (Marti et al. 1999).

Introducing the analytical expressions of the tension tensile laws of fibers [Eq. (8)] and concrete [Eq. (10)], respectively, in Eq. (7). the complete expression of the tension tensile law of the composite is obtained as a function of the generic crack width $\|$ Now, to evaluate the tensile stress level of the composite at the shear failure, the crack opening at shear collapse of the beam $\left(w_{m}\right)$ is needed.

The estimation of the crack width in the shear critical region represents a classical issue of fracture mechanics, and its value is 
strongly influenced by the dimensions of the beam reflecting the size effect. Muttoni and Ruiz (2008). in their analytical model proposed to estimate the shear strength of RC members without reinforcement, assumed that $w_{m}$ is proportional to the product of the longitudinal strain in the control depth times the effective depth of element. Previously. Casanova and Rossi (1997), on the basis of some experimental results on fibrous concrete specimens, proposed to evaluate $w_{m}$ as the product of the height of the beam $(h)$ and the strain of the longitudinal reinforcement $\left(\varepsilon_{s}\right)$. Assuming a limit value for $\varepsilon_{\text {s }}$ equal to $1 \%$. as suggested by the writers, the allowable crack opening in shear is $\omega_{m}=0.01 \mathrm{~h}$. This expression is used for the model proposed herein. Once the value of $w_{m}$ at shear failure is known, the effective tensile strength supported by fibrous concrete is calculated by Eq. (7).

It is also interesting to observe that a rearrangement of Eq. (7) provides the analytical expression of the effectiveness tensile factor

$$
v_{n}=\frac{\sigma_{n}\left(w_{m}\right)}{f_{i n}}=\underbrace{\left(1-\frac{w_{m}}{w_{n}}\right)}_{0 \cdot n_{m} w_{n}}+\left[\frac{\tan ^{-1}\left(w_{m} / \alpha\right)}{\pi}\left(1-\frac{2 w_{m}}{l_{i}}\right)^{2} F_{i}\right]
$$

\section{Simplified Design Model}

To find the critical section of the beam where the diagonal crack start to develop into the critical yield line. the equations composed of the analytical expressions of the shear capacity curve [Eq. (3)] and the average cracking stress [Eq. (4)] need to be solved. respectively. This solution may be evaluated just by a numerical approach, with the help of a simple spreadsheet.

However. the calculation may be further simplified if the correct formula for the shear capacity $[\mathrm{Eq} .(3)]$ is replaced with the following approximation:

$$
\tau_{u}=2 \frac{\tau_{c}}{(a-x) / h}
$$

where $\tau_{c}=K v_{0} f_{l}=$ load-carrying capacity for $a / h=2$ and $K$ =empirical coefficient equal to 0.059 for RC beams (Nielsen 1999).

Now, by equalizing the simplified expression of shear capacity curve for SFRC beams [Eqs. (12) and (4)], the following simple cubic equation rendering $(a-x) / h$ is obtained:

$$
\left(\frac{a-x}{h}\right)^{3}+\frac{a-x}{h}+q=0
$$

where $q=-4\left(\tau_{c} / f_{c t e f}\right)(a / h)<0$. Thus, the starting position of the critical diagonal crack $\left(a-x_{0}\right) / h$ may be evaluated in closed form as follows:

$$
\frac{a-x_{0}}{h}=\frac{i \overline{2}\left(\sqrt{12+81 q^{2}}-9 q\right)^{2}-2 i^{3}}{i \overline{6^{2}}\left(\sqrt{12+81 q^{2}}-9 q\right)^{13}} \leq \frac{a}{h}
$$

Finally, a simplified version of CSM for fibrous concrete beams (CSMf) is obtained by evaluating the shear strength of the beam by substituting the founded value of $\left(a-x_{0}\right) / h$ into Eq. (12). It is important to observe that the value of $K$ in the expression of $\tau_{c}$, is known just for RC beams and it needs an appropriate recalibration for fibrous elements. This issue is resolved in the next section.

\section{Corroboration}

A large database of more than one hundred experimental test results on SFRC beams without stirrups was compiled from literature to validate the proposed CSMf model for prediction of shear strength of rectangular fiber-reinforced concrete beams (Table 1). Only beam specimens failing in shear or with a crack pattern indicating that shear failure mode is predominant are added to the database. This condition is usually assured by a strong longitudinal reinforcement, which avoids a flexural failure and leads a brittle shear collapse (Kani 1966). By contrast, when beams are poor reinforced in bending, the longitudinal rebars yield with a consequent flexural failure of the beam. and the pullout process of fibers does not significantly enhance the bending strength of the structural element (Espion et al. 1993).

Moreover, the fiber aspect ratio $\left(l_{f} / d_{f}\right)$ was limited to the range of 40 to 133: the volume percentage of fibers $\left(V_{f}\right)$ between 0.25 and $2.00 \%$ as in the most common practical applications of fibers in construction field; the height of cross section $(h)$ to a minimum value of $150 \mathrm{~mm}$ and a maximum value of $600 \mathrm{~mm}$; and $\mathrm{a} / \mathrm{d}$ ratio in the range of 1.0 to 3.5

First. for validation of the proposed model for fibrous concrete (CSMf) beams, data have been split into two groups, depending on the material compression strength $\left(f_{c f}\right)$. In Fig. 4 , the values of the ratio between experimental results given in literature and the analytical values, predicted by using the CSMf, are reported together with its mean value and coefficient of variation (COV).

Two different values of crack sliding factor $\left(v_{s f}\right)$ have been used: the first [Figs. 4(a and b)] is the original value proposed by Zhang (1997) for plain concrete beams equal to 0.50 ; the second [Figs. $4(\mathrm{c}$ and $\mathrm{d})$ ] is chosen equal to 0.82 . The former is too conservative for normal and HSC, providing also a high value of $\mathrm{COV}$ for both concrete compression strengths. By contrast. the latter provides an accurate prediction of experimental results with a mean value of 1.01 and COV value lower for HSC. The choice of a $v_{s}$ value for fibrous concrete higher than plain concrete reflects the capacity of fibers to limit the crack slips.

In order to stress the ineffectiveness of the use of constant values for effectiveness factors in compression and tension, in Figs. 4(e and f). the results obtained by assuming $v_{c f}=v_{t f}=0.80$ suggested by Voo et al. (2006) are depicted. This value has been proposed on the basis of the experimental results obtained analyzing seven 650 - $\mathrm{mm}$ deep large-scale reactive powder concrete I-section girders without stirrups failing in shear (Voo et al. 2006). This constant value for both effectiveness factors is not able to take into account the functionally dependence of effective strength of fibrous concrete by different parameters and conditions. and the numerical results overestimate the experimental values.

To apply the proposed simplified model sCSMf, initially a numerical analysis is performed analyzing the data collected in Table 1 , and the $K$ material coefficient introduced in Eq. (12) is herein set equal to 0.110 for SFRC. The shear capacity of fibrous concrete beams may be predicted by Eq. (12) replacing $\tau_{\text {, with }}$ $\tau_{c}=0.110 v_{0 f} f, f$. Thus. introducing the value of $\left(a-x_{0}\right) / h$ in Eq. (14) into Eq. (12), the shear strength of fibrous concrete beams may be easily evaluated as follow:

$$
\tau_{u}=0.220 v_{00 f} f_{c f} h /\left(a-x_{0}\right)
$$

As an illustration of the calculation involved. consider beam B-41.()-M tested by Ashour et al. (1992). The geometrical and material properties of the beam are as follows: $b=125 \mathrm{~mm}, h$ $=2.50 \mathrm{~mm} . a / d=4 . r=3.94 \%, V_{f}=1.0 \%, l_{f} / d_{f}=60.0 / 0.8=75 . f_{c}$ 
Table 1. Details and Observed Ultimate Shear Stress of Test Specimens

\begin{tabular}{|c|c|c|c|c|c|c|c|c|}
\hline \multicolumn{3}{|c|}{ Geometry } & \multicolumn{2}{|c|}{ Steel reinforcement } & \multicolumn{2}{|c|}{ Fibers } & \multirow[b]{2}{*}{$\begin{array}{c}f_{f f} \\
(\mathrm{MPa})\end{array}$} & \multirow[b]{2}{*}{$\begin{array}{l}T_{\text {t, }} \times \mathrm{xp} \\
\text { (MPa) }\end{array}$} \\
\hline $\begin{array}{l}b \\
(\mathrm{~mm}) \\
\end{array}$ & $\begin{array}{c}h \\
(\mathrm{~mm})\end{array}$ & $a / d$ & $\begin{array}{c}\rho \\
(\%) \\
\end{array}$ & $\begin{array}{c}f_{\mathrm{y}} \\
\text { (MPa) }\end{array}$ & $\begin{array}{c}V_{1} \\
(\%)\end{array}$ & $l_{f} / d_{f}$ & & \\
\hline \multicolumn{9}{|c|}{ Mansur et al. (1986): hooked ended fibers } \\
\hline 150 & 225 & 2.0 & 1.34 & 462 & 0.50 & 60 & 29.1 & 2.54 \\
\hline 150 & 225 & 2.8 & 1.34 & 462 & 0.50 & 60 & 29.1 & 1.78 \\
\hline 150 & 225 & 3.6 & 1.34 & 462 & 0.50 & 60 & 29.1 & 1.52 \\
\hline 150 & 225 & 2.0 & 1.34 & 462 & 0.75 & 60 & 29.9 & 2.88 \\
\hline 150 & 225 & 2.8 & 1.34 & 462 & 0.75 & 60 & 29.9 & 2.03 \\
\hline 150 & 225 & 2.8 & 2.00 & 462 & 0.75 & 60 & 29.9 & 2.20 \\
\hline 150 & 225 & 2.8 & 1.34 & 462 & 0.75 & 60 & 20.6 & 1.5 .3 \\
\hline 150 & 225 & 2.8 & 2.00 & 462 & 0.75 & 60 & 20.6 & 2.103 \\
\hline 150 & 225 & 2.8 & 1.34 & 462 & 0.75 & 60 & 33.4 & 2.54 \\
\hline 150 & 225 & 2.8 & 2.00 & 462 & 0.75 & 60 & 33.4 & 2.91 \\
\hline \multicolumn{9}{|c|}{ Narayanan and Darwish (1987): crimped ended tibers } \\
\hline 85 & 150 & 2.0 & 2.00 & 530 & 0.25 & 100 & 52.5 & 2.96 \\
\hline 85 & 150 & 2.5 & 2.00 & 5.30 & 0.25 & 100 & 52.5 & 2.67 \\
\hline 8.5 & 150 & 3.0 & 2.00 & 53() & 0.25 & 100 & 52.5 & 2.77 \\
\hline 85 & 150 & 2.0 & 2.00 & 530 & 0.25 & 100 & 33.9 & 2.71 \\
\hline 85 & 150 & 2.5 & 2.00 & 530 & 0.25 & 100 & 33.9 & 2.07 \\
\hline 85 & 150 & 3.0 & 2.00 & 530 & 0.25 & 100 & 33.9 & 1.94 \\
\hline 85 & 150 & 3.0 & 2.00 & 530 & 0.50 & 133 & 52.5 & 3.23 \\
\hline 8.5 & 150 & 3.0 & 2.00 & 53() & 1.00 & 133 & 60.8 & 3.66 \\
\hline 85 & 150 & 3.0 & 2.00 & 53() & 0.50 & 1.33 & 36.0 & 1.97 \\
\hline 85 & 150 & 3.0 & 2.00 & 5.30 & 1.00 & 100 & 35.2 & 2.97 \\
\hline 85 & 150 & 2.5 & 2.00 & 530 & 0.50 & 133 & 52.5 & 3.69 \\
\hline 85 & 150 & 3.5 & 2.00 & 5.30 & 0.50 & 133 & 47.4 & 2.61 \\
\hline 8.5 & 150 & 2.0 & 2.00 & 530 & 1.00 & 133 & 57.1 & 5.57 \\
\hline 85 & 150 & 2.5 & 2.00 & 530 & 1.00 & 133 & 57.1 & 4.42 \\
\hline 85 & 150 & 3.5 & 2.00 & 530 & 1.00 & 133 & 61.1 & 2.97 \\
\hline 85 & 150 & 3.0 & 3.69 & 530 & 0.50 & 133 & 47.4 & 2.96 \\
\hline 85 & 150 & 3.1 & 5.72 & 530 & 0.50 & 133 & 47.4 & 3.55 \\
\hline 85 & 150 & 3.0 & 3.69 & 530 & 0.50 & 133 & 36.0 & 2.24 \\
\hline 85 & 150 & 3.1 & 5.72 & 5.30 & 0.50 & 133 & 36.0 & 2.33 \\
\hline 85 & 150 & 3.0 & 3.69 & 530 & 1.00 & 133 & 61.1 & 4.37 \\
\hline 85 & 150 & 3.1 & 5.72 & 53() & 1.00 & 133 & 61.1 & $5 .(0)$ \\
\hline 85 & 150 & 3.1 & 5.72 & 530 & 1.50 & 100 & 57.0 & 4.85 \\
\hline 85 & 150 & 3.1 & 5.72 & 5.30 & 2.00 & 100 & 47.5 & 4.93 \\
\hline 85 & 150 & 3.0 & 3.69 & 530 & 1.50 & 100 & 57.0 & 4.46 \\
\hline 85 & 150 & 2.0 & 5.72 & 53() & 0.50 & 100 & 50.4 & 5.46 \\
\hline 85 & 150 & 2.0 & 5.72 & 5.30 & 1.00 & 100 & 51.0 & 6.77 \\
\hline 85 & 150 & 2.0 & 5.72 & 530 & 1.50 & 100 & 57.0 & 7.15 \\
\hline 85 & 150 & 2.0 & 5.72 & 530 & 2.00 & 100 & 47.5 & 6.30 \\
\hline \multicolumn{9}{|c|}{ Lim et al. (1987): hooked ended tibers } \\
\hline 152 & 254 & 2.5 & 1.2() & 445 & 0.50 & 60 & 34.0 & 1.73 \\
\hline 1.52 & 254 & 1.5 & 2.40 & 44.5 & 1.00 & 60 & 34.0 & +.39 \\
\hline 152 & 254 & 2.5 & $2 .+0$ & 44.5 & 1.00 & 60 & 34.0 & 2.46 \\
\hline 152 & 254 & 3.5 & 2.40 & 44.5 & 1.00 & 60 & 34.0 & $2 .(0)$ \\
\hline 152 & 254 & 1.5 & 2.40 & 445 & 0.50 & 60 & 34.0 & 4.02 \\
\hline 152 & 254 & 2.5 & 2.40 & 445 & $(0.50$ & 60 & 34.0 & 1.90 \\
\hline 152 & 254 & 3.5 & 2.40 & $4+5$ & 0.50 & 60 & 34.0 & 1.47 \\
\hline \multicolumn{9}{|c|}{ Ashour et al. (1992): hooked ended tiber } \\
\hline 125 & 250 & 1.0 & 2.84 & 460 & 0.50 & 75 & 99.0 & 9.09 \\
\hline 125 & 250 & 2.11 & 2.84 & 460 & 0.50 & 75 & 99.1 & 4.82 \\
\hline
\end{tabular}


Table 1. (Continued.)

\begin{tabular}{|c|c|c|c|c|c|c|c|c|}
\hline \multicolumn{3}{|c|}{ Geometry } & \multicolumn{2}{|c|}{ Steel reinforcement } & \multicolumn{2}{|c|}{ Fibers } & \multirow[b]{2}{*}{$\begin{array}{c}f_{f f} \\
(\mathrm{MPa})\end{array}$} & \multirow[b]{2}{*}{$\begin{array}{c}\tau_{H, \cdot \mathrm{wP}} \\
(\mathrm{MPa})\end{array}$} \\
\hline $\begin{array}{l}\text { b) } \\
(\mathrm{mm})\end{array}$ & $\begin{array}{c}h \\
(\mathrm{~mm})\end{array}$ & $a / d$ & $\begin{array}{c}\rho \\
(\% / \%)\end{array}$ & $\begin{array}{c}f \\
(\mathrm{MPa})\end{array}$ & $\begin{array}{l}V_{1} \\
(\%)\end{array}$ & $l / d$ & & \\
\hline 125 & 250 & 4.0 & 2.84 & 460 & 0.50 & 75 & 95.4 & 2.27 \\
\hline 125 & 250 & 2.0 & 2.84 & 460 & 1.00 & 75 & 95.3 & 6.06 \\
\hline 125 & 250 & 4.0 & 2.84 & 460 & 1.00 & 75 & 97.5 & 3.17 \\
\hline 125 & 250 & 2.0 & 4.58 & 470 & 1.00 & 75 & 94.5 & 6.73 \\
\hline 125 & $25 \%$ & 4.0 & 4.58 & 470 & 1.00 & 75 & 93.8 & 3.88 \\
\hline \multicolumn{9}{|c|}{ Minelli (2005): hooked ended fibers } \\
\hline 200 & 480 & 2.5 & 1.04 & 512 & 0.38 & 50 & 24.8 & 1.49 \\
\hline $2(x)$ & 480 & 2.5 & 1.04 & 512 & 0.64 & 48 & 61.1 & 2.14 \\
\hline \multicolumn{9}{|c|}{ Li et al. 11992): hooked ended tibers } \\
\hline 127 & 228 & 3.0 & 2.20 & 4.50 & 1.00 & 60 & 22.7 & 3.05 \\
\hline $6+$ & 127 & 3.0 & 2.20 & +50 & 1.00 & 60 & 22.7 & 3.16 \\
\hline 64 & 127 & 3.0 & 1.10 & 4.50 & 1.00 & 60 & 22.7 & 2.43 \\
\hline 64 & 127 & 1.5 & 2.20 & 4.50 & 1.00 & 60 & 22.7 & 5.64 \\
\hline 127 & 228 & 3.0 & 2.20 & 450 & 1.00 & 60 & 26.0 & 3.05 \\
\hline 64 & 127 & 3.0 & 2.20 & 4.50 & 1.00 & 60) & 26.0 & 3.55 \\
\hline \multicolumn{9}{|c|}{ Sharma (1986): hooked ended tibers } \\
\hline 150 & 300 & 2.0 & 1.61 & 400 & 1.00 & 83 & 48.6 & 3.03 \\
\hline \multicolumn{9}{|c|}{ Imam et al. (1998): hooked ended fibers } \\
\hline $2(x)$ & 350 & 2.5 & 1.87 & 5.50 & 0.75 & 75 & 110.0 & 4.48 \\
\hline 200 & 350 & 1.8 & 3.08 & 550 & 0.75 & 75 & 109.5 & 8.80 \\
\hline 200 & 350 & 2.5 & 3.08 & 5.50 & 0.75 & 75 & 110.0 & 4.74 \\
\hline 200 & 350 & 3.5 & 3.08 & 5.50 & 0.75 & 75 & 111.5 & 3.48 \\
\hline 200 & 350 & 4.5 & 3.08 & 5.50 & 0.75 & 75 & 110.8 & 3.53 \\
\hline \multicolumn{9}{|c|}{ Noghabai $(2(0)(0)$ : hooked ended tibers } \\
\hline 200 & $3(0)$ & 2.8 & 4.3() & 5() 0 & 1.00 & 50 & 91.4 & 6.60 \\
\hline 200 & 500 & 2.9 & 3.00 & 590 & 1.00 & 86 & 76.8 & 3.81 \\
\hline 200 & $5(0)$ & 2.9 & 3.00 & 590 & 0.50 & 86 & 69.3 & 3.51 \\
\hline 200 & 500 & 2.9 & 3.00 & 590 & 0.75 & 86 & 68.0 & 3.85 \\
\hline $3(0)$ & 700 & 3.0 & 2.90 & 590 & 0.75 & 86 & 60.2 & 2.98 \\
\hline \multicolumn{9}{|c|}{ Kwak et al. (2002): hooked ended libers } \\
\hline 125 & 250 & 2.0 & 1.52 & $4+2$ & 0.50 & 63 & 63.8 & 5.09 \\
\hline 125 & 250 & 2.0 & 1.52 & $4+2$ & 0.75 & 63 & 68.6 & 5.44 \\
\hline 125 & 250 & 2.0 & 1.52 & $4+2$ & 0.50 & 63 & 30.8 & 4.04 \\
\hline 125 & 250 & 3.0 & 1.52 & $4+2$ & 0.50 & 63 & 30.8 & 2.55 \\
\hline \multicolumn{9}{|c|}{ Cho and $\mathrm{Kim}(200) 3)$ : hooked ended tibers } \\
\hline 120 & $2(0)$ & 1.4 & 1.30 & 399 & 0.50 & 60 & 25.7 & 3.03 \\
\hline 120 & 200 & 1.4 & 1.30 & 399 & $1.00)$ & 60 & 25.3 & 3.95 \\
\hline 120 & 200 & 1.4 & 1.30 & 399 & 1.50 & 60 & 23.9 & 4.19 \\
\hline 120 & 200 & 1.4 & 1.30 & 399 & 0.50 & 60 & 57.8 & 4.74 \\
\hline 120 & 200 & 1.4 & 1.30 & 399 & 1.00 & 60 & 61.5 & 5.12 \\
\hline 120 & 20() & 1.4 & 2.90 & 4.56 & 0.50 & 60 & 70.5 & 8.90 \\
\hline 120 & 200 & 1.4 & 2.90 & 4.56 & $1 .(0)$ & 60) & 67.3 & 8.43 \\
\hline 120 & 200 & 1.4 & 2.00 & $4+2$ & 0.50 & 60 & 82.4 & 7.86 \\
\hline 120 & 200 & 1.4 & 2.00 & $4+2$ & 1.00 & 60 & 81.1 & 8.01 \\
\hline 12() & 200 & 1.4 & 2.90 & 343 & 0.50 & 60 & 86.1 & 7.64 \\
\hline 120 & 200 & 1.4 & 2.90 & $3+3$ & 1.00 & 60 & 89.4 & 8.49 \\
\hline
\end{tabular}


Table 1. (Continued.)

\begin{tabular}{|c|c|c|c|c|c|c|c|c|}
\hline \multicolumn{3}{|c|}{ Geometry } & \multicolumn{2}{|c|}{ Steel reinforcement } & \multicolumn{2}{|c|}{ Fibers } & \multirow[b]{2}{*}{$\begin{array}{c}f_{f} \\
(\mathrm{MPa})\end{array}$} & \multirow[b]{2}{*}{$\begin{array}{c}\tau_{\text {Tacup }} \\
\text { (MPa) }\end{array}$} \\
\hline $\begin{array}{l}b \\
(\mathrm{~mm}) \\
\end{array}$ & $\begin{array}{c}h \\
(\mathrm{~mm}) \\
\end{array}$ & $a / d$ & $\begin{array}{c}\rho \\
(\%)\end{array}$ & $\begin{array}{c}f_{i} \\
\text { (MPa) }\end{array}$ & $\begin{array}{l}V_{1} \\
(\%)\end{array}$ & $1 / 1 d_{1}$ & & \\
\hline \multicolumn{9}{|c|}{ Cucchiara et al. (20)4): hooked ended fibers } \\
\hline 150 & 250 & 2.8 & 1.90 & 610 & 1.00 & 60 & 40.9 & 2.93 \\
\hline 150 & 250 & 2.8 & 1.90 & 610 & 2.00 & 60) & 43.2 & 3.15 \\
\hline 150 & 250 & 2.0 & 1.90 & 610 & 1.00 & 60 & 40.9 & 3.50 \\
\hline 1.50 & 250 & 2.0 & 1.90 & 610 & 2.00 & 60 & 43.2 & 3.52 \\
\hline \multicolumn{9}{|c|}{ Rosenbusch and Teutsch (2003): hooked ended fibers } \\
\hline 200 & 300 & 3.5 & 3.56 & 400 & 0.20 & 67 & 49.9 & 2.12 \\
\hline 200 & 300 & 3.5 & 3.56 & $4(x)$ & 0.40 & 67 & 46.5 & 2.31 \\
\hline 200 & 300 & 3.5 & 3.56 & 4() & 0.60 & 67 & 51.3 & 2.98 \\
\hline 200 & $3(0)$ & 3.5 & 2.83 & $50(0$ & 0.50 & 67 & 32.1 & 2.34 \\
\hline 200 & 450 & 3.3 & 3.08 & 500 & 0.50 & 67 & 32.1 & 1.78 \\
\hline 200 & 500 & 3.4 & $2 .+1$ & 500 & 0.50 & 67 & 32.1 & 1.61 \\
\hline 200 & 600 & 3.5 & 2.73 & 500 & 0.50 & 67 & 32.1 & 1.98 \\
\hline 200 & 300 & 1.5 & 1.81 & 400 & 0.25 & 67 & 4.3 .7 & 1.59 \\
\hline 200 & 300 & 1.5 & 1.81 & 400 & 0.75 & 67 & 42.8 & 1.70 \\
\hline 200 & 300 & 2.5 & 1.15 & $+(0)$ & 0.25 & 67 & 42.5 & 0.77 \\
\hline 200 & 300 & 2.5 & 1.15 & 400 & 0.75 & 67 & 41.1 & 1.00 \\
\hline 200 & 300 & 2.5 & 1.81 & $4(0)$ & 0.25 & 67 & 42.5 & 1.00 \\
\hline 200 & 300 & 2.5 & 1.81 & $4(0)$ & 0.75 & 67 & 41.1 & 1.34 \\
\hline 200 & 300 & 4.0 & 1.81 & $+(0)$ & 0.25 & 67 & 43.7 & 1.26 \\
\hline 200 & 300 & 4.0 & 1.81 & 400 & 0.75 & 67 & 42.8 & 1.79 \\
\hline
\end{tabular}

$=93.8 \mathrm{MPa}$. and experimental average shear stress at failure $\tau_{u \text { exp }}=3.88 \mathrm{MPa}$. In the following, steps of calculation of shear strength are illustrated:

1. Using Eq. (5) determines the effectiveness factor in compression $v_{0 t}=0.55$ and calculate $\tau_{c f}=0.110 v_{0 f} f_{c f}=5.66 \mathrm{MPa}$ :

2. For the effectiveness factor in tension. first estimate the shear crack width $w_{m,}=0.01 h=2.50 \mathrm{~mm}$, then using Eq. (11) to obtain $v_{1 /}=0.74$ and. consequently, the effective tensile strength is $f_{\left(t, e^{\prime}\right)}=v_{t f} f_{t, t}=2.37 \mathrm{MPa}$ :

3. Calculate the $q=-4(\tau, f(a))(a / h)$ coefficient to be $q=-33$. Now, using Eq. (14), find $\left(a-x_{0}\right) / h=3.10$; and

4. Finally, find the analytical average shear stress at failure using Eq. (15) $\tau_{u \text {.anl }}=3.65 \mathrm{MPa}$.

Note that all calculations involved are simple in nature and no iterations are needed.

In Figs. 5( $\mathrm{a}$ and $\mathrm{b}$ ), the comparison between experimental and analytical results for normal- and high-strength fibrous concrete beams provided by the proposed simplified design model sCSMI is shown. The simplified model is able to predict the shear strength of SFRC beams without stirrups with good accuracy. and the values of mean and COV are close to the corresponding statistical parameters obtained using the "exact" formulation of CSMf.

A comparison of predicted shear strength has been carried out by using the following semiempirical formulations known in literature: Sh86 (Sharma 1986): ND87 (Narayanan and Darwish 1987): AA90 (Al-Ta' an and Al-Feel 1990); AWH92 (Ashour et al. 1992): IVM98 (Imam et al. 1998): KS99 (Khuntia et al. 1999): KEKKO2 (Kwak et al. 2002): CLP()6 (Campione et al. 2006). In Fig. 6, a summary of statistical coefticients (mean and COV values) obtained by formulations considered for the comparison, is reported with the corresponding values calculated for the proposed model (CSMf) and the simplitied design model (sCSMf) too. For the CSMf, two different values of the sliding reduction factors have been used again. namely $v_{s t}=0.50$ and $v_{s t}=0.82$ : and results obtained using a constant value (Voo et al. 2006) for the effectiveness factors in compression and tension $\left(v_{c f}=v_{t f}=(0.80)\right.$ are reported as well.

An analysis of the numerical results reported in Figs. 3-5 and their relative statistical coefficients are summarized in Fig. 6. and lead to some considerations. Several semiempirical formulations provide numerical results with the mean value far from the unit value and large scatter of data. highlighting the incapacity of most of this kind of formulations to capture the physical mechanism of shear failure. By contrast. the numerical analyses performed by the CSMf show the primary role of sliding reduction factor $\left(v_{y}\right)$ to achieve good numerical performances, emphasizing the physical nature of the proposed model. A high value of sliding factor $\left(v_{v}=0.82\right)$ takes into account the ability of fibers to contain slips along crack surface and crack width, providing a very low COV both for normal and high fibrous concrete strength beams. In addition. the approximation introduced in the proposed design model (sCSMf) does not affect the ability of proposed formulation to provide a good estimation of average ultimate shear stress of fibrous beams without stirrups.

Further observations need to be made on the results in Fig. 6 about the only three models able to provide an accurate prediction of shear strength. The ND87 is less conservative than CSMf in predicting the shear capacity of normal-strength fibrous concrete beams. For high-strength fibrous concrete beams. KEKKO2 and CLP06 models give a good estimation of shear capacity. with the mean value and $\mathrm{COV}$ equal to 1.00 and 0.26 , respectively, for the KEKKO2 model. All three formulations may be classified as semiempirical models, obtained extending known relationships originally proposed for $\mathrm{RC}$ beams, to the case of fibrous concrete. The ND87 power equation contains several terms, which depend 


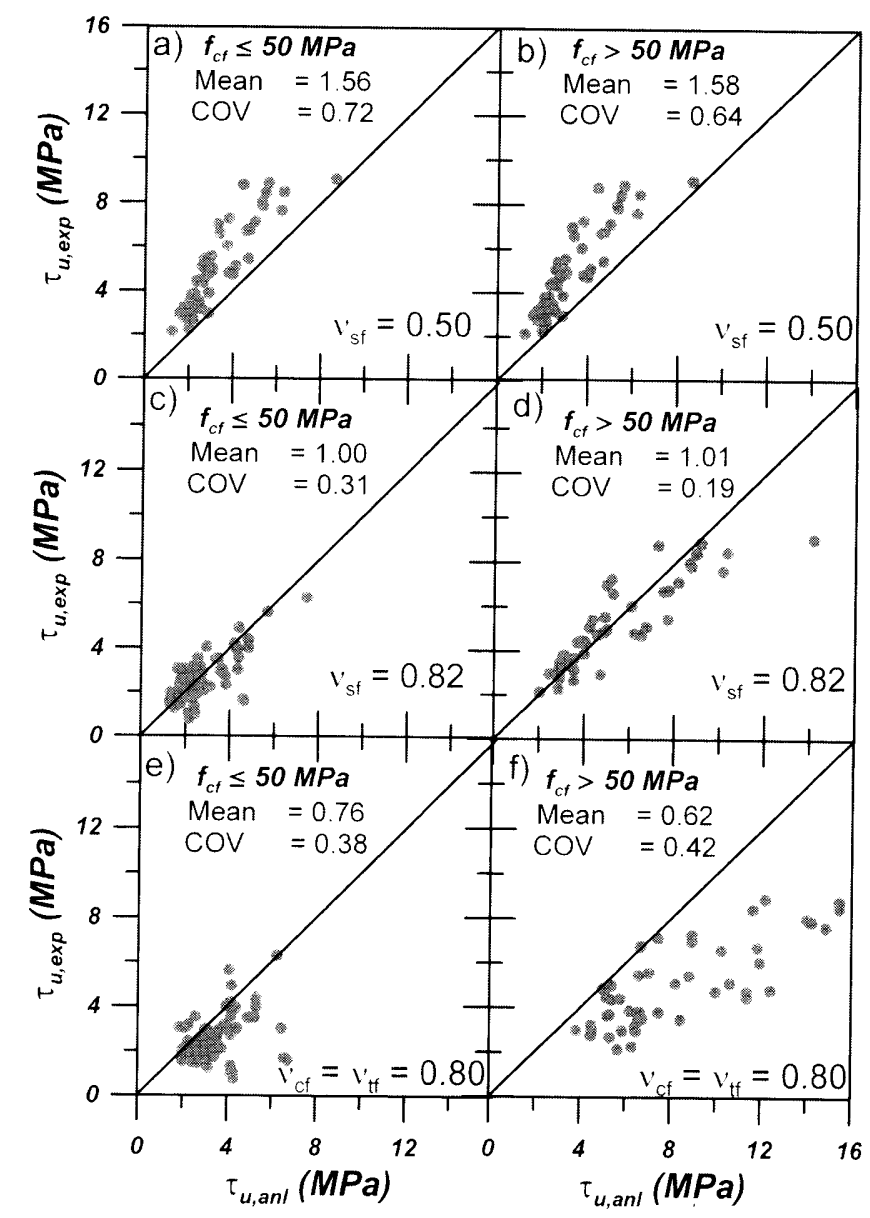

Fig. 4. Comparison between experimental and analytical results for normal- and high-strength fibrous concrete beams with different values of effectiveness factors

by concrete strength and geometrical percentage of longitudinal reinforcement. Furthermore. a dependence by $a / h$ ratio just for short beams. as done herein the proposed model, is also included. Over a calibration of the equation's coefficients Narayanan and Darwish (1987). to take into account the fibers contribute to shear strength of SFRC beams, include additional terms as function of split cylinder strength of fiber concrete and fiber mechanical and geometrical properties. The latter proposing the fiber factor $F$ $=\beta V_{f}\left(l_{f} / d_{f}\right)$, previously mentioned, which strongly influences the contribution of fibers to the ultimate shear stress, as suggested by Narayanan and Darwish (1987). This formulation, despite its empirical nature. provides good results at predicting the shear capacity of SFRC beams without stirrups. Moreover, the performance achieved by KEKK02 model. substantially derived by a recalibration of empirical coefficients of ND87 equation for high-strength fibrous concrete, confirm the goodness of the equation form originally proposed by Narayanan and Darwish (1987).

\section{Conclusions}

A simple mechanical model has been proposed for shear capacity prediction of fibrous concrete beams without stirrups under transversal loads. The model has been derived on the basis of plastic theory and limit analysis and takes into account the fiber concrete contribution to shear strength. including the high residual post cracking tensile strength of SFRC. To this aim. the constitutive

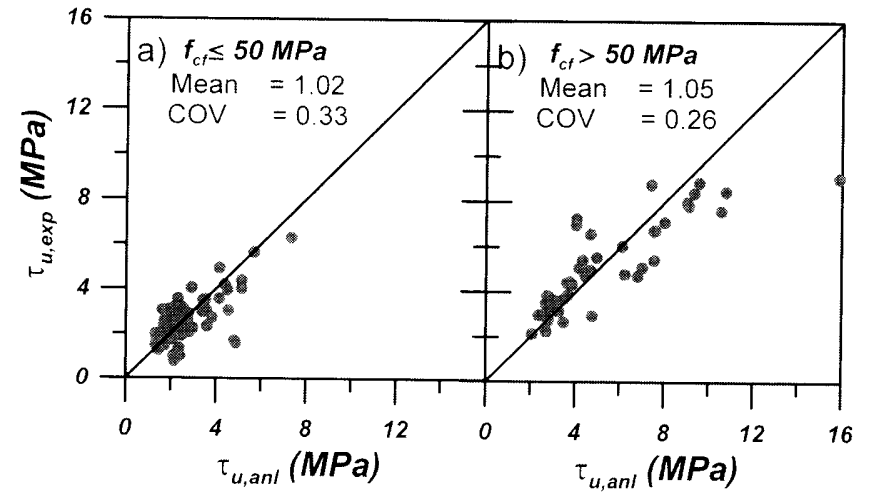

Fig. 5. Comparison between experimental and analytical results for normal- and high-strength fibrous concrete beams performed by the simplified design proposed model

law suggested by Foster et al. (2006) has been adapted to formulate an analytical expression of effectiveness factor of fibrous concrete in tension. which includes geometrical and mechanical properties of fibers, and takes into account the influence of size effect in the shear strength of SFRC beams.

In the proposed model. the effectiveness factor of fibrous concrete in compression has been modified for deep beams. by reintroducing the additional term depending on the shear span-depth ratio existing in the original plastic solution. but herein only for $a / h \leqslant 2.6$. The reduction slide factor for fiber concrete, $v_{s /}$. has been increased to 0.82 . to take into account the ability of fibers in reducing slips along shear cracks. The very low values of COV obtained, both for normal and high fibrous concrete strength beams. highlights the physical role played by $v_{s f}$ in the evaluation of shear strength of SFRC beams. Further study might be necessary to evaluate the contribution of fibers to the shear resistance mechanism of short beams more accurately.

Introducing a simplification in the analytical equation of shear capacity curve [Eq. (3)], a handy design formula has been proposed The comparison between experimental and analytical values of ultimate average shear stress shows the ability of the simplified design model to determine, in a simple closed form. both the collapse strength of SFRC beams and the cross section where the critical diagonal shear crack starts from the bottom face

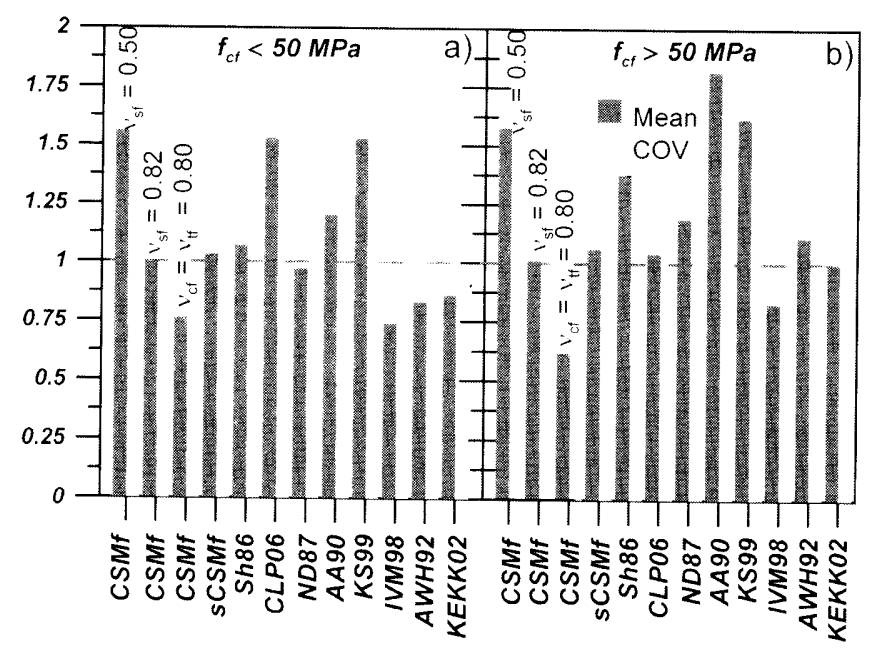

Fig. 6. Statistical comparison of models for shear capacity of normat- and high-strength fibrous concrete beams 
of the beam. The simplified model may serve as a easy tool for designers, providing a fast estimation of SFRC beam shear capacity.

\section{Notation}

The following swmbols are used in this paper:

$A_{s}=$ longitudinal reinforcement area:

$a=$ shear span:

$a_{\ldots}=$ maximum aggregate size:

$b . d, h=$ width. effective depth, and height of beam cross section:

$d_{f}, l_{f}=$ diameter and length of fiber:

$F . F_{\tau}=$ fiber factors:

$f_{1 .} f_{c, t}=$ cylinder and effective compressive strength of concrete:

$f_{c f} \cdot f_{c t}=$ cylinder compressive strength and direct tensile strength of fibrous concrete:

$f_{c t i}, f_{c t h t)}=$ direct and effective tensile strength of fibrous concrete:

$f_{(r)} f_{(t, c)}=$ direct and effective tensile strength of concrete:

$f_{v}=$ yielding stress of rebars reinforcement:

$G_{C}=$ fracture energy for plain concrete:

$K=$ empirical coefficient in the simplified design model:

$I_{\text {" }}=$ initial length of embedment of the fiber:

$M_{n} \cdot M_{f l}=$ ultimate and nominal flexural capacity:

$P_{t}=$ force in a single fiber:

$P_{11}, P_{1 r}=$ ultimate and cracking load:

$r=A_{\checkmark} / b h=$ geometrical percentage of longitudinal reinforcement:

$u$ = relative displacement along the critical diagonal crack:

$V_{1}=$ fiber volume percentage:

$W_{i}, W_{t}=$ internal and external work:

$u=$ crack opening:

$w_{c}, w_{m}=$ engagement length and crack opening at shear failure:

$u_{t s}=$ crack opening at direct tensile failure of plain concrete;

$x . x_{0}=$ distance between the support and generic and critical crack:

$\alpha=$ fibrous material parameter:

$\beta . \beta_{\tau}=$ fiber bond factors:

$\gamma=$ diagonal crack angle:

$\varepsilon_{\mathrm{s}}=$ strain of the longitudinal reinforcement:

$v_{t}, v_{t}=$ effectiveness factors for concrete in compression and in tension;

$v_{t f}, v_{t f}=$ effectiveness factors for fibrous concrete in compression and in tension:

$v_{s}, v_{y}=$ crack sliding factors for plain and fibrous concrete:

$\theta=$ fiber inclination angle:

$\rho=A_{1} /$ hd $=$ geometrical percentage of longitudinal reinforcement:

$\sigma_{i}, \sigma_{f}, \sigma_{f t}=$ tensile tension of concrete. fibers and fibrous concrete:

$\tau_{1}=$ mean shear stres belween fiber and matrix:

$\tau_{r} . \tau_{f}=$ load-carrying capacity for $a / h=2$ for plain and tibrous concrete heams:

$$
\begin{aligned}
\tau_{u \text { uxp }} \cdot \tau_{u \text { anl }}= & \text { experimental and analytical ultimate shear } \\
& \text { stress; and } \\
\tau_{u} \cdot \tau_{u}= & \text { ultimate and cracking shear stress. }
\end{aligned}
$$

\section{References}

Al-Ta'an. S. A.. and Al-Feel. J. R. (1990). "Evaluation of shear strength of fiber reinforced concrete beams." Cem. Concr. Compos. 12.8794.

American Concrete Institute (ACI). (1983). "Building code requirements for reinforced concrete." ACI 3/8-83. Detroit.

American Concrete Institute (ACI). (2008). "Building code requirements for structural concrete and commentary." $\mathrm{ACI}$ 3/8-08. Detroit.

Ashour, S. A.. Hasanain. G. S.. and Wafa. F. F. (1992). "Shear behaviour of high strength fiber reinforced concrete." ACI Struct. J.. 89(2). $176-$ 184.

Campione. G.. La Mendola. L.. and Papia. M. (20)6). "Shear strength of fiber reinforced beams with stirrups." Struct. Eng. Mech.. 1. 107-1,36.

Casanova. P.. and Rossi. P. (1997). "Analysis and design of steel tiber reinforced concrete beams." ACI Mater. J.. 94(5), 595-60)2.

Cho. S.. and Kim. Y. (20)3). "Effect of steel fibers on short beams loaded in shear." ACl Struct. J.. 100(6), 765-774.

Cucchiara. C.. La Mendola. L.. and Papia, M. (2004). "Effectiveness of stirrups and steel fibers as shear reinforcement." Cem. Concr. Compos.. 26. 777-786.

Espion. B.. Devillers. J.-J.. and Halleux. P. (1993). "On the use of steel fibers as complementary reinforced concrete beams in bending." Mater: Struct.. 26(162), 479-485 (in French).

Foster, S. J., Voo, Y. L., and Chong. K. T. (2006). "FE analysis of steel tiber reinfored concrete beams failing in shear: Variable engagement model." ACI SP-237. Detroit, 55-70).

Imam. M.. Vandewalle. L.. and Mortelmans. F. (1998). "Shear-moment analysis of reinforced high strength concrete beams containing steel fibers." Can. J. Cir: Eng.. 22. 462-470.

Kani. G. N. J. (1966). "Basic facts concerning shear failure." ACI J. 6.316). 67.5-692

Khuntia. M. Stojadinovic. B., and Subhash. C. G. (1999). "Shear strength of normal and high-strength fiber reinforced concrete beams without stirrups." ACl Struct. J.. 96(2), 282-289.

Kwak. Y. K.. Eberhard. M. O.. Kim. W. S.. and Kim. J. (2002). "Shear strength of steel fiber-reinforced concrete beams withoul stirrups." ACI Struct. J.. 99(4), 530-538

L.i. V. C.. Ward. R.. and Hamza. A. M. (1992). "Steel and synthetic tibers as shear reinforcement." ACI Mater: J., 89(5). 499-508.

Lim. T. Y.. Paravasivam. P.. and Lee. S. L. (1987). "Shear and moment capacity of reinforced steel-fiber-concrete beams." Mag. Concr: Res. $39(140) \cdot 148-160)$

Mansur. M. A.. Ong. K. C. and Paramasivam. P. (1986). "Shear strength of fibrous concrete beams without stirrups." J. Struct. Eng. 112(9). $2066-2079$

Marti. P.. Pfyl. T. Sigrist. V., and Ulaga. T. (1999). "Harmonized test procedures for stecl fiber-reinforced concrete." ACl Mater: J.. $96(6)$. 676-685.

Minelli. F. 2005). "Plain and fiber reinforced concrete beams under shear loading: Structural behavior and design aspects." Ph.D. thesis. Iniv of Brescia. Italy.

Muttoni. A.. and Ruiz, M. F. (20)8). "Shear strength of members withou transverse reinforcement as function of critical shear crack width." ACl Struct. J., $105(2), 16.3-172$

Narayanan. R.. and Darwish. I. Y. S. (1987). "Use of steel fibers as shear reinforcement." ACl Struct. J.. 84(3). 2066-2079)

Nielsen. M. P. (1999). Limit analysis and concrete plasticity. Ind Ed. CRC. Boca Raton. Fla.

Noghahai. K. (200(0). "Beams of fibrous concrete in shear and bending: experiment and model." J. Struct. Eng. 126(2). 243-251.

Rosenbusch. J.. and Teutsch. M. (2003). "Shear design with $(\sigma-\varepsilon)$ 
method." Proc.. Int. RILEM Workshop on Test and Design Methods for Sted riber Reinforced Concrete. RILEM Publications SARI. Bochum. $105-117$.

Russo. (j.. Zingone. (j.. and Puleri, G. (199)1). "Flexure-shear interaction model for longitudinally reinforced beams." ACI Siruct. J.. $88(1)$, $66-68$.

Sharmal. A. K. (1986). "Shear strength of steel tiber reinforced concrete beams." ACI /.. 83(4). 624-628.

Thomas. J.. and Ramaswamy. A. $120(06)$. "Shear strength of prestressed concrete T-beams with steel fiber over partial/full depth." ACI Struct. I. $103(3) .+27-435$.

Vecchio, F. J. (20)(0). "Analysis of shear critical reinfored concrete beams." ACI Struct. J., 97(1), 102-110.

Vecchio. F. J. (200()b). "Disturbed stress field model for reinforced concrete: Formulation." J. Struct. Eng.. 126(9), 1070-1077.

Vecchio. F. J.. and Collins. M. P. (1986). "The modified compression tield theory for reinforced concrete elements subjected to shear." $\mathrm{ACl}$ Struct. J.. 83(2), 219-231.

Voo, Y. L.. Foster. S. J.. and Gilbert. R. I. (2006). "Shear strength of tiber reinforced reactive powder concrete prestressed girders without stirrups." J. Ad: Concr: Technol., 4(1). 123-132.

Zhang. J.-P. (1997). "Diagonal cracking and shear strength of reinforced concrete beams." Mag. Concr: Res.. 49(178), 55-65. 